\title{
latrogenic Rupture Uterus with Bowel Prolapse - Missmanaged Third Stage of Labour
}

\author{
SHAMSUN NAHAR ${ }^{1}$, NASREN AKTHER ${ }^{2}$, PALASH KUMAR DAV ${ }^{3}$, \\ MAMUNI SULTANA ${ }^{4}$, DILIP KUMAR KUNDU ${ }^{5}$
}

\begin{abstract}
:
We present a case of mismanaged $3^{\text {rd }}$ stage of labour by untrained dai who delivered the patient by injudicious administration of uterotoric drug and tried to remove the placenta manually with excavation of the small intestine through vagina.

Every women present a unique challenge during her pregnancy and delivery period, unfortunately a significant number will have medical and surgical problems which will complicate their pregnancy and puerperal period, develop such serious condition that the lives of both mother and their unborn baby will be threatened. The aim of this case presentation are to ensure the ANC for every women and facilitate to make informed decision concerning where they will be seen, who will undertake the case, which screening test to be done, where they plan to give birth and where she will achieve full facility for safe delivery. These helps to prevent the catastrophic complications.
\end{abstract}

Key ward: Mismanaged third stage of labour, Complication of third stage of labour

\section{Introduction:}

Third stage of labour is defined as the period after delivery of baby upto delivery of placenta and membranes. Third stage includes separation, descent and expulsion of the placenta with its membrane. Average duration is $15 \mathrm{~min}$ but reduced to $5 \mathrm{~min}$ by active management. In third stage there may be catastrophic complications which can threaten maternal health and can lead to maternal death. These are postpartum hemorrhage (PPH) retained placenta, shock - hemorrhagic/ non hemorrhagic, pulmonary embolism (amniotic/air) and uterine infection. Beside these, iatrogenic complications can happen. During the process of labour uterine rupture (tear in the wall of the uterus), can happen; most often in obstructed labour or at the site of a previous scar, like C-section incision, myomectomy incision and rare by a history of MR or DE \& C perforation ${ }^{1,2}$. It is a potentially serious complication for both the mother and the baby. Fetal morbidity and mortality occur as a result of catastrophic hemorrhage leading to fetal anoxia. In the last decade, Bangladesh has made remarkable progress towards Millennium Development Goal 5 (MDG5) with a $40 \%$ reduction in the maternal mortality ratio (MMR) from 320 to 194 maternal deaths per 100000 live births. ${ }^{3}$ Poor access to good-quality care is considered to be one of the main reasons for the relatively high percentage of deliveries conducted by skilled birth attendants (SBA) in Bangladesh. Access to facility-based skilled birth attendance and emergency obstetric care may be hampered by three delays first described by Thaddeus and Maine. ${ }^{4}$ These include delays related to decision making at community level, delays in reaching the hospital as well as delays in receiving professional care once woman has arrived at the hospital.

Here we present a case of iatrogenic uterine trauma with bowel prolapse; which had been done by untrained birth attendant by injudicious administration

1. Professor \& Head of the Department Gynae \& Obs. Khulna Medical College.

2. Senior consultant, Department of Gynae \& Obs. Khulna Medical College Hospital.

3. Assistant Registrar. Department of Surgery. Khulna Medical College Hospital.

4. Registrar Department of Gynae \& Obs. Khulna Medical College Hospital.

5. Assistant Professor Department of Anesthesia Khulna Medical College Hospital.

Address of Correspondence: Prof. Dr. Shamsun Nahar, Professor \& head of the Department Gynae \& Obs. Khulna Medical College. 
of uterotonic drug followed by ruptured uterus and extraction of small bowel through the ruptured site during an attempt of manual removal of placenta.

\section{Case report:}

Mrs. Ritu, 21 years of age, Para2-2 ( 1 still birth, 1 Anencephaly), housewife of a low socioeconomic condition came from Jibannagar, Chuadanga got admitted in the Khulna Medical College Hospital $(\mathrm{KMCH})$ on 5th February, 2017 with history of home delivery by untrained Dai 10 hours back, and small bowel hanging through vagina during the process of manual removal of placenta. According to the statement of pt's attendant, she was carrying 36 weeks pregnancy. It was her planned pregnancy, but she had no antenatal checkup in this pregnancy. Her pregnancy was uneventful up to 36 weeks. But

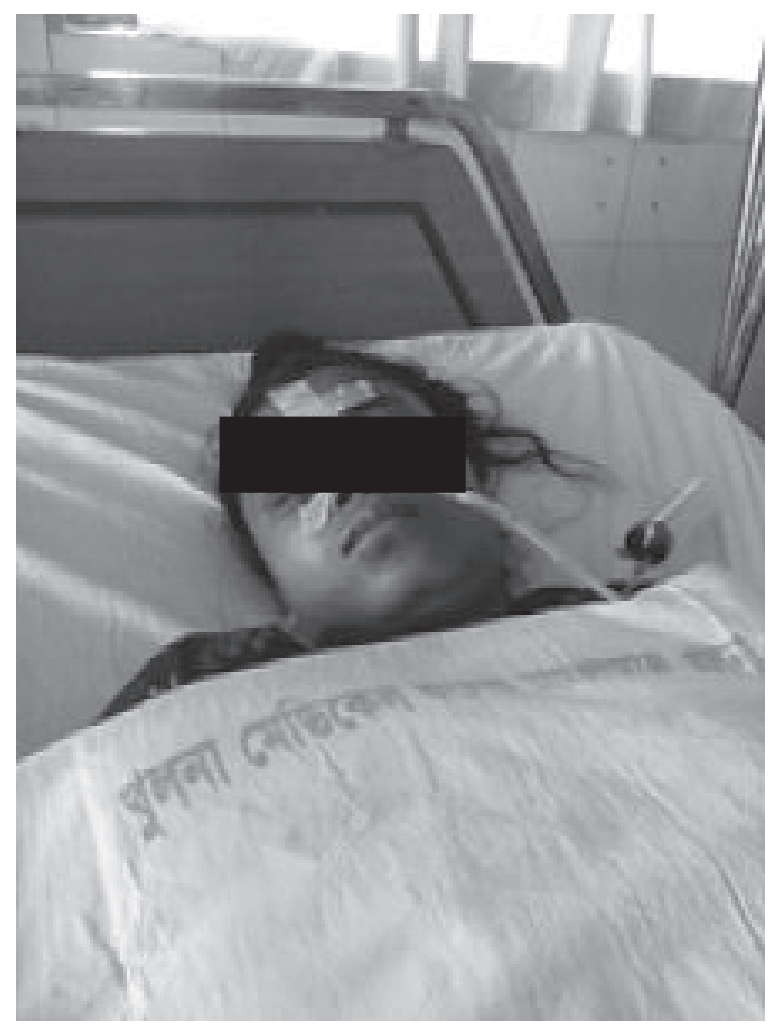

on the day before admission, sudden rupture of membrane occurred at midnight with rhythmic uterine contraction. She was attended by a village doctor and untrained Dai in her home and treated with some oral drugs and intra venous injections but couldn't mention their name. A dead anencephaly fetus was delivered after 5 hours but placenta was retained and Dai tried manual removal of placenta but failed and she extracted some part of small intestaine. Patient condition gradually deteriorated, she was shifted to Jibannagar UHC, from there to Jessore Medical College, where resuscitation was done with 3 units blood transfusion, after seeing the large loop of intestine outside the vagina the patient was referred to $\mathrm{KMCH}$ for further management.

On admission in $\mathrm{KMCH}$, the patient was in shock. Abdomen was distended and tender. PV examination reveals about $40-50 \mathrm{~cm}$ intestine hanging out through the vagina. Immediate resuscitation antibiotic therapy followed by laparotomy was done in Khulna medical college. Huge amount of blood clot was removed from the peritoneal cavity and a transverse rupture was found on the fundus of uterus which extended up to posterior uterine wall. Loops of intestine enters into the uterine cavity through the ruptured site and intact placenta with membrane was expelled out through

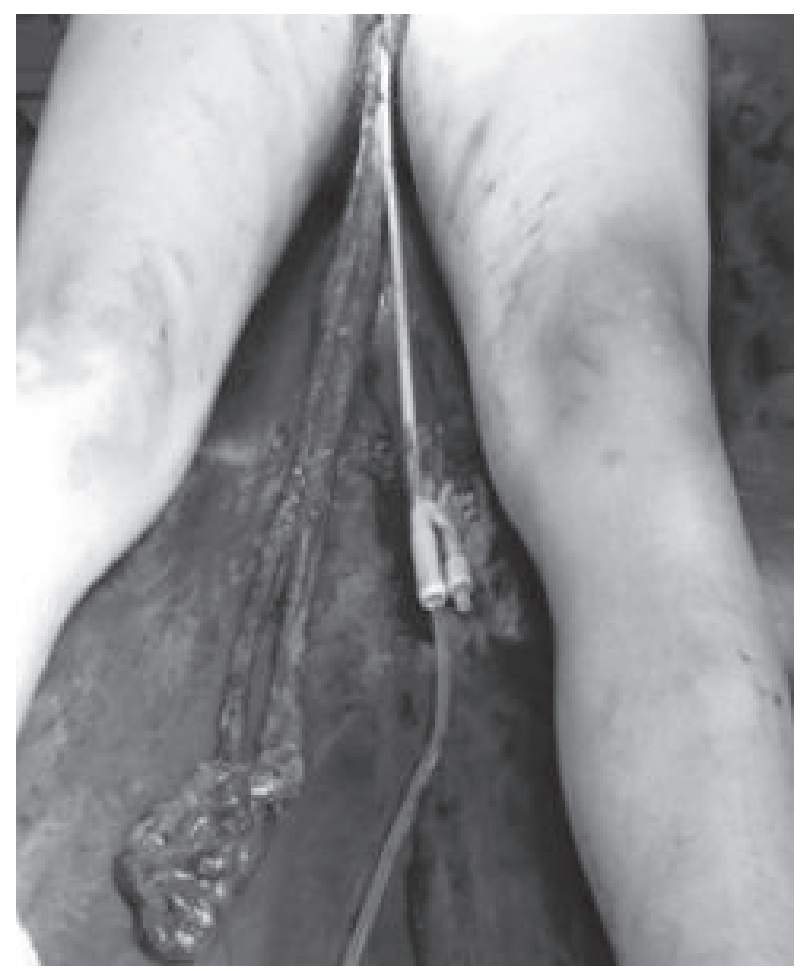

Lope of small gut outside the vagina.

the hole in the uterus and was found in the sub diaphragmatic area.

Subtotal hysterectomy followed by resection of about $50 \mathrm{~cm}$ of jejunum and ileum with anaestomosis and ileostomy was done by joint collaboration of consultant surgeon and gynecologist. Her postoperative period was uneventful and patient was monitored both clinically and biochemically. Patient was discharged 


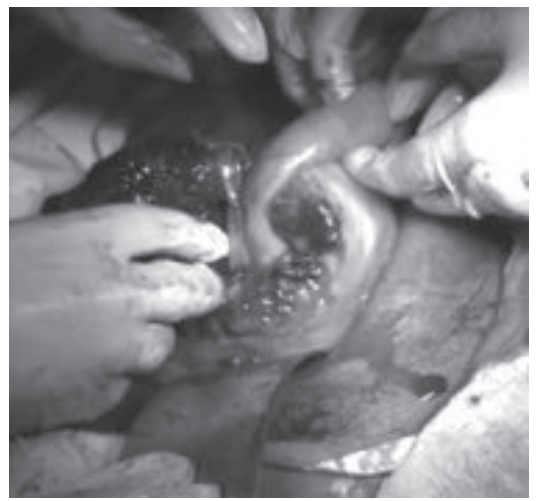

Placenta and cord outside the uterus.

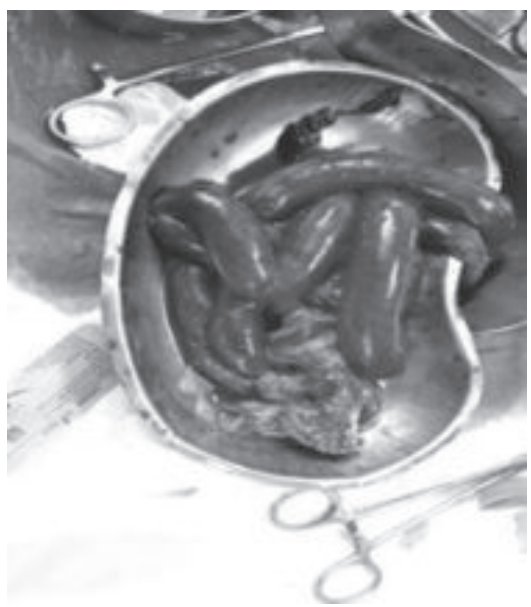

Fundal rupture with intestine inside.

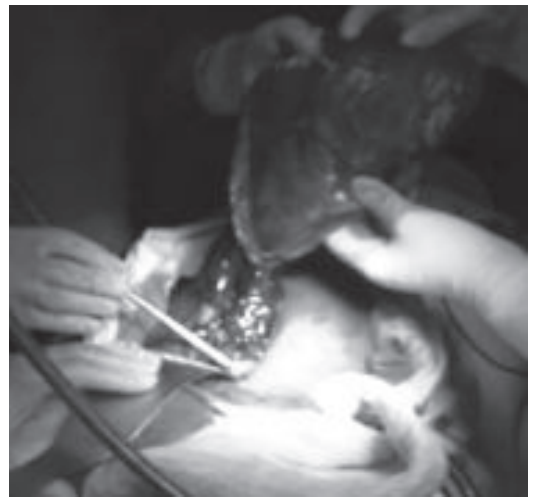

Excised intestine. on the $10^{\text {th }}$ POD and advised to come for follow up after 2 months for ilestomy closer.

\section{Discussion:}

In our country the majority of the home delivery is (about $80-90 \%$ ) are conducted by unskilled birth attendant, Traditional Birth Attendents (TBAs) and by patient relatives. In about eighty-five per cent of cases, the delivery remains uncomplicated and uneventful but in the remaining cases unforeseen complication may arise which require urgent and skilled management to prevent the maternal mortality and also morbidity. In 1928, a pregnant women faced a 1 in 290 chance of dying from an obstetric complication related to the pregnancy; the most recent confidential enquiry into Maternal and Child Health put this figure at 1 in $19,020^{5}$. Undoubtedly, good antenatal and delivery care has made a significant contribution to this reduction. In Bangladesh three-quarters of mothers had received antenatal care on at least one occasion and a similar proportion were reported to have sought care for a life-threatening obstetric complication. Hence, although women do not use health facilities for delivery, they do access these services when complications arise. A. Halim et all study revealed that most mothers who had a complication actually sought care and either died at facility level or in transit. ${ }^{6}$ This is contrary to earlier findings from Bangladesh where most maternal deaths were reported to have occurred at home, in our country $17 \%$ of mothers who died on the way to/from a facility, we were unable to differentiate between deaths occurring on the way from home to a health facility or in transit from one health facility to another.
Findings from a study conducted in India revealed that $18 \%$ of mothers who died in transit, $11.5 \%$ died while being referred between health facilities. Effective antenatal care and planning for delivery including skilled midwife and place of delivery can reduce the delivery hazards but to get an optimum outcome, adequate supervision with partographic monitoring in intranatal period and postnatal care is mandatory. Recent Maternal Mortality Rate (MMR) in our country is $194 / 100000$ live birth ${ }^{3}$. This rate can be reduced if we ensure all women in institutional delivery, ideally, all women should have institutional delivery. The national socio-demographic goals and the millenium development goals (MDG 4\&5) aimed by 2015 to achieve $100 \%$ deliveries conducted by skilled birth attendant (SBA) and to reduce maternal mortality ratio below 100 and prenatal death rate below $30^{7,8}$.

To reduce the maternal mortality morbidity our aim will be strengthen our activities by making large number of skilled birth attendant, improve midwife sector with enabiling environment. Facilities should be available specially in skilled surgical team with anesthetist and blood transfusion. In all upazilla hospital transport facilities should be available to establish proper referal facility. But still there is long way to go to make motherhood safe in Bangladesh and developing countries like us. This patient is mismanaged during her delivery by unskilled dai with injudicious administration of uterotonic drug and during the process of manual removal of placenta uterus was injured and large part of intestine came out through the vagina. Ultimately patient was survived 
due to proper transfer and quick services of Obs Gynae team in $\mathrm{KMCH}$. Thus, the teaching hospitals and the district or sub-district hospitals are mostly being utilized as referral hospital where most of the neglected cases are rushed late and in a bad shape.

\section{Conclusion:}

Improving the quality of care at community and health facility level is urgently needed and likely to result in further reduction in maternal morbidity \& mortality in Bangladesh. A maternal death is not only a personal loss it is a social injustice and a failure on the part of health services.

\section{References:}

1. Renrew MJ et al: practices that minimize trauma to the genital track in childbirth: A systematic review of the literature. Birth 1998:25:143

2. D.C Datta - Text book of obstetrics includes Perinatotoy and contraception. Seventh edition 2011. Editor Hiralulkonac, publisher new ceases book agency (P) Ltd. Kolkata-700009. Page 139.

3. ICDDRB, NIPORT. Bangladesh Maternal Mortality and Health Care Survey. 2010. [www.icddrb.org/what-we-do/health- programmes/populationsciences/ bmms-2010final-report]. Accessed 29 November 2013. Kobiinsky M, Anwar I, Mridha MK, Chowdhury ME Botlero R: Reducing maternal mortality and improving maternal health: Bangladesh and MDG 5. J Health PopulNutr2008;26:280.

4. Thaddeus S, Maine D. Too far to walk: maternal mortality in context. SocSci Med:2010-994;38. 1002-1110.

5. Confidential Enquiry into Maternal and Child Health (2004) Why Mothers Die; 2000-2002. London: RCOG Press. 3: 11-12

6. Halim A., Utz B, Biswas A, Rahman A, Van; Ven Den Broek N: Cause of and contributing factors to maternal deaths; a cross-sectional study using verbal autopsy in four districts in Bangladesh. Royal College of Obstetricians and Gynaecologists. 2014. Page 86-94.

7. World Health Organization; Evaluation of WHO Contribution to Maternal Health in the South East Asia Region, 2016.

8. National Health Service (2001) The Pregnancy Book. London Health Promotion England. 